\title{
OS FUNDAMENTOS FILOSÓFICOS DA CRÍTICA TEATRAL DE MACHADO DE ASSIS
}

\section{ALEX LARA MARTINS}

Instituto Federal do Norte de Minas Gerais

Almenara, Minas Gerais, Brasil

Resumo: O jovem Machado de Assis acumulou capital cultural filosófico suficiente para debater sobre as principais questões teóricas do país em meados do século XIX. Machado adquiriu o capital cultural da filosofia eclética, mobilizando-o para a emissão dos pareceres no Conservatório Dramático e para a composição de um critério pelo qual pudesse conceber e julgar uma obra literária. O objetivo deste artigo é rastrear os fundamentos filosóficos que compõem essa maneira de julgar e de fazer literatura. A estratégia metodológica consiste em realizar um cruzamento de informações entre a produção filosófica brasileira e o modo como a crítica machadiana sobre o drama recepciona e redireciona esses discursos.

Palavras-chave: filosofia; ecletismo; teatro; Machado de Assis.

\section{THE PHILOSOPHICAL FOUNDATIONS OF MACHADO DE ASSIS'S THEATER CRITICISM}

\begin{abstract}
The young Machado de Assis accumulated enough philosophical cultural capital to discuss the main theoretical issues of his country in the mid-nineteenth century. Machado engaged his eclectic cultural capital to issue opinions for the Dramatic Conservatory, and compose, more or less coherently, a criterion by which he could judge a literary work. The purpose of this paper is to trace the philosophical foundations that make up this way of judging and creating literature. The methodological strategy used here consists of cross-referencing Brazilian philosophical production and the way Machadian criticism receives and redirects these assumptions.
\end{abstract}

Keywords: philosophy; eclecticism; theater; Machado de Assis. 
bram-se as cortinas para um público curioso sobre o destino de seu herói. O cenário imita o cárcere do Santo Ofício. O prisioneiro está deitado sobre palhas, acorrentado, aguardando a promessa de morte. Ouve-se um ruído de ferrolho. Um homem encapuzado, com dois buracos diante dos olhos quase invisíveis, aconchega-se para a última oração.

Assim tem início o último ato do primeiro drama brasileiro: a encenação de Antônio José ou o poeta e a inquisição, do eclético romântico Gonçalves de Magalhães, estreou com grande impacto a 13 de março de 1838. Essa tragédia serviu como propaganda nacionalista para o movimento romântico. Nascido no Rio de Janeiro, o teatrólogo Antônio José da Silva, conhecido por "O Judeu", foi torturado e condenado pela Inquisição por supostas heresias. Aos 21 anos assinara o termo de arrependimento prometendo nunca blasfemar contra o catolicismo. Promessa falsa, pois continuou a dedicar-se a combater as práticas do Santo Ofício contra os cristãos-novos. No auge de sua carreira, ele foi recolhido novamente pela Inquisição, degolado e queimado em praça pública. Assim, o Judeu se tornou o herói político e literário das gerações seguintes de escritores. Machado de Assis presta-lhe homenagem numa sextilha de aspecto filosófico, que termina em oximoro: "Pois que já riste, chora" (ASSIS, 2015a, p. 562).

Estudos recentes sobre a presença da filosofia na obra de Machado de Assis evidenciam a sabedoria do Eclesiastes, o ceticismo de Pascal e o pessimismo de Schopenhauer (MAIA NETO, 2007; CEI, 2016; MARTINS, 2017). Na poesia citada, observa-se a referência de que nada há de novo sob o sol, a transitoriedade das coisas contrárias que afetam o ser humano e a comparação entre os sentidos trágicos da vida e da morte do comediógrafo. Esses estudos, no entanto, detêm-se sobre a sua obra romanesca, relegando o processo de formação filosófica das décadas de 1850 e 1860, período no qual predominam a poesia e o teatro. Até 1866, Machado publicara duas traduções, Queda que as mulheres têm para os tolos e Os trabalhadores do mar, um livro de poesia, Crisálidas, duas comédias avulsas, Quase ministro e Os deuses da casaca, e um volume sobre o teatro, contendo duas peças e as cartas críticas trocadas com Quintino Bocaiuva. No caso dos gêneros poético e dramático, Machado teve de lidar com a discussão sobre o desenvolvimento do romantismo e a oposição que lhe fez o naturalismo ou realismo. O que não está claro, no que diz respeito às concepções teóricas de Machado de Assis, é a contraparte filosófica dessa disputa estético-literária, a saber, o desenvolvimento do ecletismo espiritualista e os seus conflitos com o Positivismo. O objetivo deste artigo é traçar os fundamentos teóricos da crítica 
Machado de Assis em Linha — Universidade de São Paulo

http://machadodeassis.fflch.usp.br

teatral machadiana recorrendo à produção filosófica franco-brasileira de meados do século XIX.

Os intelectuais brasileiros se defrontaram com questões de ordem política, estética, religiosa e filosófica. Liberta de Portugal, a ex-colônia teve de se preocupar com o modelo monárquico de governança e com a construção de um conjunto de costumes e crenças que a distinguiam enquanto sociedade. O período joanino havia acentuado a distância entre os portugueses - que mantinham junto ao rei o prestígio que lhes assegurava o poder - e a elite local, para quem o desejo de nobreza não se concretizava. Havia também uma questão de fundo religioso, que colocava em xeque a autoridade moral e política da Igreja Católica dentro de uma organização social com instituições pretensamente livres. O clero nacional, pouco regular, deitava suas raízes em múltiplas ordens, congregações e paróquias, florescendo uma força política algumas vezes insurreta contra Roma e a Coroa. Além disso, a questão da identidade político-estética dessa novíssima nação não poderia ser um ato contínuo lusitano. Os conceitos e as teses sobre o que é ser brasileiro levou os intelectuais à expressão de uma nova literatura, com temas e gêneros textuais adequados à geografia nacional.

O ecletismo espiritualista, tal como proposto por Victor Cousin (1854, p. 15), caiu como uma luva para a realidade local. Essa filosofia ofereceu a resposta adequada para as questões teóricas com as quais se defrontavam os intelectuais brasileiros, ao providenciar uma solução de compromisso entre os setores políticos radicais, promover o movimento de particularização cultural via romantismo e estabelecer as regras de conduta moral através das práticas político-religiosas adequadas à realidade brasileira. A doutrina de Cousin oferecia um método compreensivo da história do espírito humano. Originalmente, o ecletismo pretendeu articular elementos de diversas doutrinas filosóficas e científicas, destacando-se pela tentativa de harmonizar teses materialistas e espiritualistas, realistas e idealistas. Essa teoria surgiu em nome do movimento de restauração filosófica das verdades fundamentais demolidas pelas correntes criticistas da virada para o século XIX. De maneira geral, os ecléticos espiritualistas estavam de acordo com a existência de substâncias imateriais, o caráter espiritual dos fundamentos da ética e a irredutibilidade do conhecimento intelectual à sensação. Tratavam de pôr em relevo os erros e os acertos das teses filosóficas, de visualizar o progresso dialético do espírito, através de suas diversas figuras, em direção ao Absoluto, considerando-se a capacidade humana de adquirir verdades. 
Do ponto de vista político, essa filosofia mitigava a força das cláusulas fundamentais do liberalismo econômico e político, num país presumivelmente sem condições efetivas para realizá-las (PAIM, 1997, p. 374). O filósofo estrangeirado Silvestre Pinheiro Ferreira propôs uma solução conciliatória entre conservadores e reformistas ao consolidar os princípios da monarquia constitucional, no Manual do cidadão num governo representativo. A autoridade da Igreja Romana foi temperada pela doutrina regalista, pela qual o imperador intervinha favoravelmente ao clero nacional, que nutria interesses muitas vezes divergentes da Santa Sé. Do ponto de vista estético, a solução ecletista consistia em reduzir a autêntica expressão de nacionalidade à busca interior de certos instintos primitivos - por exemplo, a ideologia indianista - ou da consciência aguçada de pertencimento histórico-social. Isso porque valia a tese filosófica de Gonçalves de Magalhães (2004, p. 283), um dos expoentes do ecletismo espiritualista brasileiro, segundo a qual "a literatura de um povo é o desenvolvimento do que ele tem de mais sublime nas ideias, de mais filosófico no pensamento, de mais heroico na moral, e de mais belo na natureza".

As escolas do drama ofereceram dois encaminhamentos para a tese de Magalhães. Para dar exemplos efetivos, o teatro de Martins Pena introduziu a "comédia de costumes", uma espécie de sátira social sobre a realidade das classes baixas. Gonçalves Dias manteve o gosto pela cor local e pelo pitoresco, estudando o índio por aquilo que ele pretensamente possuía de original. Apesar desses dois caminhos distintos, o desvio em relação a uma possível influência da cultura lusitana direcionava os românticos à adoção de padrões estéticos franceses, num período em que, paradoxalmente, os próprios franceses, adeptos do espiritualismo de Victor Cousin, desconfiavam dos novos e dos velhos padrões.

Os intelectuais franceses, amparados pela influente Revue des Deux Mondes, não abraçavam as doutrinas do romantismo nem expressavam boasvindas ao realismo teatral. Se o ecletismo, como quer Antonio Paim (1997, p. 70), "foi uma espécie de filosofia oficial do Segundo Reinado", a Revue foi o órgão mediador entre esse modelo de pensamento e a possibilidade de os intelectuais brasileiros a ele se adaptarem. As variantes ecléticas nacionais, quais sejam, a teoria romântica de Gonçalves de Magalhães, a teoria salvacionista de Monte Alverne e as teorias políticas de Pinheiro Ferreira, foram tentativas de conciliar, respectivamente, a cultura tradicional e o progresso, cânones católicos e a necessidade de ajustes anticlericais, a unidade nacional e os princípios econômicos liberais em voga no estrangeiro. No caso 
Machado de Assis em Linha — Universidade de São Paulo

http://machadodeassis.fflch.usp.br

de Machado de Assis, essa revista teve influência decisiva para a superação dos critérios estéticos de românticos e de naturalistas.

Machado foi desde cedo um teórico do teatro brasileiro. A "bossa do filosofismo" (ASSIS, 1859, p. 8) ${ }^{1}$ - expressão utilizada pelo crítico teatral em $O$ espelho para se referir ao seu método analítico - trouxe-lhe mais resultados positivos do que suas primeiras obras teatrais, Desencantos (1861), Hoje avental, amanhã luva (1860), O caminho da porta (1863), Protocolo (1863), Quase ministro (1863), Os deuses da casaca (1865) e As forcas caudinas. ${ }^{2}$ Vendose diante daquela encruzilhada escolástica, ele pôde seguir o método ecletista e sugerir uma saída por portas espiritualistas, ou seja, passou a refletir sobre $o$ teatro, em seu aspecto universalista, mais do que escolher e realizar um teatro.

O jovem crítico acompanhou de perto as inovações do drama realista brasileiro, trazido à cena pelo Teatro Ginásio Dramático, a partir de 1855, com peças de Dumas Filho, Émile Augier e Octave Feuillet. Esses dramaturgos se autodenominavam realistas porque pretendiam descrever com rigor a nova sociedade burguesa. Com a verve moralista, suas peças estabeleciam enredo que discriminava bons e maus costumes através do conjunto de valores como o trabalho, a família, o casamento, o dinheiro, a livre iniciativa, a necessidade de preservação do capital, a honestidade etc. Tratava-se de uma dramaturgia inovadora em relação ao teatro de João Caetano dos Santos, que apostava em dramas românticos, tragédias neoclássicas e melodramas de sucesso em vez de investir seriamente no teatro nacional.

Foi o Ginásio Dramático, criado pelo empresário Joaquim Heleodoro dos Santos, que trouxe à cena a comédia de costumes da alta classe, peças sérias interpretadas com o máximo de naturalidade, fazendo prevalecer o bom senso burguês "para que o palco se transforme em uma tribuna, um espaço para o debate de ideias sobre a vida em família e em sociedade. O objetivo desse debate: regenerar, moralizar e educar o espectador" (FARIA, 2008, p. 155). O crítico reformador deveria assumir as tarefas do Conservatório Dramático Brasileiro, instituição de censura ligada ao governo que ombreava

\footnotetext{
${ }^{1}$ A série de críticas teatrais "Revista de teatros" não foi coletada pelas Obras completas em quatro volumes. Para as críticas teatrais não incluídas nesta edição, consultou-se a coletânea de João Roberto Faria (ASSIS; FARIA, 2008).

${ }^{2}$ Forcas caudinas é uma comédia em dois atos descoberta por Eugênio Gomes (1953) e publicada por Magalhães Júnior na coleção Contos sem data (1956). Há uma cópia autógrafa dessa peça, provavelmente de 1863. Ela serve de base para o conto "Linha reta, linha curva", publicado originalmente no Jornal das Famílias e, em seguida, reunido nos Contos fluminenses (1870). Encenada pelo Teatro Ateneu Dramático, Caminho da porta foi a primeira peça original de Machado, uma vez que Hoje avental, amanhã luva é uma imitação e Desencantos foi publicada apenas em livro. Deuses da casaca e Quase ministro foram representadas apenas em saraus literários. Ver Faria (2008).
} 
Machado de Assis em Linha — Universidade de São Paulo

http://machadodeassis.fflch.usp.br

com o Instituto Histórico e Geográfico Brasileiro em sua ocupação de forjar os recursos culturais do país. Eram instituições de governo ecléticas, isto é, conservadoras em relação à arrumação social, progressistas em relação à garantia e ao estímulo das liberdades fundamentais do homem. Machado percebe o delicado equilíbrio entre ordem e anarquia, poder e autonomia, moralismo e liberdade. Daí a importância de instituições balanceadas, nos termos ecléticos de Machado, de um "Conservatório ilustrado":

A literatura dramática tem, como o povo constituído, um corpo policial, que lhe serve de censura e corretivo: é o Conservatório.

Dois são, ou devem ser os fins desta instituição; o moral e o intelectual. Preenche o primeiro na correção das feições menos decentes das concepções dramáticas; atinge ao segundo analisando e decidindo sobre o mérito literário - dessas mesmas concepções. (ASSIS, 2015e, p. 1014)

Antes de participar dos quadros da instituição, Machado considerava, no entanto, que o Conservatório fazia bem apenas a censura moral. Após quase vinte anos de funcionamento, desbalanceara, tornando-se mero aparato de polícia. Viciado em sua própria burocracia, ele quase não podia exercer a "função civilizadora" e praticar a "emancipação do espírito". Ficou sem inteligência para julgar a própria inteligência, "o mérito puramente literário, no pensamento criador, na construção cênica, no desenho dos caracteres, na disposição das figuras, no jogo da língua" (ASSIS, 2015e, p. 1015). Por seu turno, o jovem crítico julgava o teatro pelo critério da utilidade, ou seja, por seu alcance moral $e$ por seu mérito literário. Na prática, fazer censura ilustrada, repressão libertadora e moderação progressista não eram ações contraditórias. Com a pena na mão, Machado elogiou dramas que condenavam a escravidão e possuíam algum sentimento democrático e liberal, peças com "iniciativa" e "contra a velha religião da arte" (ASSIS; FARIA, 2008, p. 145). Apesar da novidade formal, a proposta dramatúrgica dos autores realistas era pouco ou nada progressista. Numa interpretação puramente sociológica, a prescrição de valores da burguesia emergente seria o que importamos e julgamos ter de moderno, embora as ideias liberais devessem se retratar ao que impunha a circunstância histórica, mais ou menos àquilo que Roberto Schwarz (1991, p. 40) denominou "travejamento contraditório da experiência". Mas uma análise detida sobre a história das ideias revela que o liberalismo e a prescrição moral da alta classe francesa para uma plateia que infringia a regra, por exemplo, no modo de produção escravista, não eram coisas contraditórias, mas complementares sob a perspectiva do ecletismo. 
Alguém pode alegar que a própria perspectiva eclética era uma ideologia que mascarava a contradição real entre este modo de produção e o esclarecido. Seja como for, um dos motivos que levaram Machado de Assis a desacreditar da tese realista forte, segundo a qual o escritor deve comprometer-se com a descrição acurada da realidade social, foi a inviabilidade teórica de adotar a perspectiva romântica, então ultrapassada. Considera-se que a solução se desenhará nas Memórias póstumas, em que o narrador assume a perspectiva cética, zombando e fazendo equipolência tanto da norma quanto da infração.

Entre a percepção do problema e a proposta de solução, Machado buscou amparo teórico em dois articulistas da Revue: Gustave Planche e Émile Montégut. Até mesmo o título de sua coluna sobre a cena teatral no jornal $O$ Espelho é copiado de Montégut, redator da Revue des Theatres. Os teóricos franceses discutiam quais eram os objetivos do teatro. Para eles a arte dramática não fora concebida com o propósito de corrigir os costumes nem servir de entretenimento. Antes de tudo, o teatro deveria se preocupar com a verdade, a beleza e a bondade, os pilares da filosofia cousiniana. De acordo com Planche, as construções dos caracteres das peças modernas pareciam estranhas para a vida comum e para o entendimento do crítico. Além disso, a formação de caráter do público era um objetivo secundário da arte:

[o] que há de mais lastimável no estado atual da literatura dramática é que o público não leva o teatro a sério. Quero dizer que ele o assiste por mero divertimento, não atribuindo às obras dramáticas a importância literária [...]. É um fato lamentavelmente comprovado que devemos constatar: enquanto a produção dramática for o que é hoje, não podemos esperar que o gosto do público se eleve ou se apure. (PLANCHE, 1856, p. 700-701, tradução nossa)

Montégut é tido por crítico "bem severo", mas, de acordo com Machado, "são cabidas as suas censuras ao nosso país, em cujo teatro se legitimam as versões espúrias e mal alinhavadas" (ASSIS; FARIA, 2008, p. 265). O crítico brasileiro se refere a uma tradução malfeita de uma peça de Augier que já desagradara na França. A severidade de Montégut nas páginas da Revue é provavelmente derivada de sua reprovação ao movimento realista, responsável pela crise do bom gosto do público:

Eu sei que o sistema de realismo dramático tem um mérito incontestável, o qual eu certamente não poderei contestar: o de dispensar o autor de imaginação, de invenção e de pensamento. (MONTÉGUT, 1859b, p. 970, tradução nossa) 
Planche era o "mais ilustre crítico da escola clássica", possuía um "alto critério" e servia à "verdadeira causa da arte" (ASSIS; FARIA, 2008, p. 390). Com o conhecimento atualizado, Machado de Assis é admitido no Conservatório Dramático, o mesmo que criticara anteriormente. De 1862 a 1864, ele atuou como censor e emitiu diversos pareceres, resmungando, vez por outra, dos limites que a própria instituição repressora lhe impunha (MASSA, 1971, p. 330-339). O cargo no conservatório serviu de contrapeso ao realismo e ao romantismo. Desse modo, ele podia se colocar numa posição conciliadora entre os movimentos literários em conflito:

As minhas opiniões sobre o teatro são ecléticas em absoluto. Não subscrevo, em sua totalidade, as máximas da escola realista, nem aceito, em toda a sua plenitude, a escola das abstrações românticas; admito e aplaudo o drama como a forma absoluta do teatro, mas nem por isso condeno as cenas admiráveis de Corneille e Racine. Tiro de cada coisa uma parte, e faço o meu ideal de arte, que abraço e que defendo.

Entendo que o belo pode existir mais revelado em uma forma menos imperfeita, mas não é exclusivo de uma só forma dramática. Encontro-o no verso valente da tragédia, como na frase ligeira e fácil com que a comédia nos fala ao espírito.

Com estas máximas em mão - entro no teatro. (ASSIS, 2015g, p. 1020, grifo nosso)

Franqueza e liberdade de consciência eram alguns ideais do folhetinista tomados aos articulistas da Revue ou, se quisermos, ao próprio Cousin em $\mathrm{Du}$ $v_{r a i}{ }^{3}$ Esses ideais não faziam sentido se fossem adotados abstratamente. Daí a função de instituições ecléticas, como o Conservatório, que pudessem garantir a "liberdade possível, isto é, a maior soma de liberdades que se possa outorgar, dadas as condições locais, sem pôr em risco o poder dispensador, ou melhor, garantidor das mesmas" (MACEDO, 1997, p. 110). A coexistência dessas duas visões de mundo, ainda que antagônicas para um europeu na última metade do século XIX, aqui era uma característica comum à nova inteligência. Machado de Assis julgava normal assumir atividades tão contraditórias como a de censor e a de liberal. Registre-se: a princípio, ninguém o recriminou. Apenas na segunda fase do Conservatório, nos idos de 1878, a reação liberal publicará uma charge na Semana Ilustrada, em que

\footnotetext{
${ }^{3}$ Glória Vianna (2008) registra o Du vrai, du beau et du bien (1854) na biblioteca de Machado (documento $566)$.
} 
Machado aparece ajudando a decapitar os dramaturgos com uma tesoura. Sob o ecletismo harmonizavam-se o critério estético, a busca do belo na forma puramente artística, e o critério moral, a percepção do teatro como a "escola de costumes" e a "pedra de toque da civilização" (ASSIS, 2015b, p. 224).

Desde essa época, Machado de Assis manteve uma concepção filosófica e moral do teatro. Extintos o Conservatório e as garantias oferecidas pelo governo, então toda a estrutura haveria de ser desmontada. Ele julgava a questão "na sua acepção mais abstrata" (ASSIS; FARIA, 2008, p. 254). Isso justifica teoricamente o rápido desencanto de Machado com o jornalismo político - mero produto do liberalismo econômico - e a sua preferência pela crítica teatral. A tese de que o governo deveria cuidar da cena artística fez parte de uma das discussões mais sérias sobre o teatro nacional, protagonizadas pelo ministro Sousa Ramos, conselheiro do Império, que instituiu uma comissão formada por Cardoso de Meneses e Sousa, José de Alencar e Joaquim Manuel de Macedo. A discussão excedeu os limites da comissão após a publicação do artigo de Macedo Soares (1861), para quem a cena dramática deveria se submeter aos ditames da livre concorrência. Machado polemizou com Soares, defendendo a tese da subvenção estatal do teatro brasileiro. Além disso, a concepção de Machado buscava tratar o teatro, por um lado, como uma arte sem objetivos, como expressão do que é belo e verdadeiro, e, por outro, como escola moral, com o objetivo específico de formar bons cidadãos.

A questão se colocava, naquele instante, sobre qual deveria ser a forma estética adequada para expressar aquele conteúdo moral. Até entrar no Conservatório, Machado se comprometeu com o realismo e a moral burguesa, mas logo aderiu a uma tese menos exclusiva, admitindo que o conteúdo artístico deveria seguir critérios gerais e abstratos. Apesar disso, algo se manteve durante todo o período de amadurecimento crítico. Digamos que o mérito literário sempre se resumiu à harmonia da seguinte tríade: dramaturgia, atuação e recepção do público. O crítico teatral tornou-se um equilibrista de três diferentes peças: o primeiro malabar era "a construção dos caracteres", que deveria nortear o lançamento da segunda peça, a própria interpretação do ator; por último, o crítico verificava se à mimese seguia a estese ou a capacidade do público de apreender e compartilhar as expressões do artista.

O centro de gravidade da crítica se localizava, portanto, no trabalho do ator, intermediário do ideal artístico e da sensibilidade do auditório. Machado de Assis tanto admirava as interpretações de Gabriela da Cunha que o biógrafo 
Magalhães Júnior (2008, p. 137-152) supôs, da parte daquele, uma paixonite oculta. Diz Machado: foi ela "a primeira que nos revelou os belos trabalhos do teatro moderno francês" (ASSIS, 2015d, p. 37). O bom ator corrigia e aperfeiçoava um papel defeituoso. Foi esse o caso das atrizes Ludovina da Costa e Emília das Neves. A atuação da primeira compensava os "desvarios da velha escola" (ASSIS; FARIA, 2008, p. 193) romântica com seu drama inverossímil e inconsequente. Emília das Neves, atriz com qualidades que empregava os efeitos das cenas "com a discrição necessária para não cair das alturas da natureza e da arte. Sombria ou radiante, irada ou terna, amorosa ou odienta, ela sabe que, em cada uma dessas fases do sentimento, a arte exige um toque ideal" (ASSIS, 2015c, p. 177). A tríade dramatúrgica se harmonizava entre a concepção autoral comprometida com a arte, a avaliação de propriedade de ordem estética do censor, mais o trabalho de representação do ator, vetor da concepção e do conteúdo moral da obra. Quando essas coisas se conjugavam, independentemente da escola, a obra expressaria os sentimentos universalmente humanos.

Montégut também defendia a dramaturgia de caracteres ou, pelo menos, utilizava a caracterologia como critério de avaliação estética. Para o crítico francês, o fazer artístico funcionava como um efeito ou ilusão de realidade. Os artistas eram tanto melhores quanto mais alcançassem o equilíbrio entre o real e o ideal. Ao examinar, por exemplo, uma obra de É. Augier, Montégut o parabeniza por perceber que a arte do drama consiste em "conceber as partes, distribuir as cenas e combinar seus efeitos" (MONTÉGUT, 1859a, p. 748), por meio de "certo ecletismo, uma certa tentativa de conciliação e de fusão dos diversos sistemas que reinaram exclusivamente, cada qual a seu turno" (MONTÉGUT, 1860, p. 252).

Ao crítico cumpria verificar se aos preceitos da escola concordavam a definição dos tipos, a construção de uma psicologia verossímil aos acontecimentos e o esboço contrastivo dos caracteres. Foi com esses critérios extraescolares que Machado de Assis avaliou positivamente o drama Mãe, de José de Alencar, e As leoas pobres, tradução de Augier e Foussier. Nesse último caso, apesar da relevância moral "contra as pinturas contemporâneas do vício na cena", exigência da escola realista moderna, importava mais a "Verdade nos caracteres e naturalidade nas situações" (ASSIS; FARIA, 2008, p. 276). Quer dizer, pouco importavam a escola, o estilo e a nacionalidade do drama, desde que se apresentasse algo da essência volátil do ser humano, tal como descrita pelo ecletismo espiritualista. 
No Conservatório e nas críticas teatrais, Machado passava a agir como se fosse um "orientador literário" ou um esteta que construísse seu próprio critério de julgamento. $\mathrm{O}$ aperfeiçoamento de um método analítico parecerlhe-á uma fixação desde as próprias composições dramáticas até os primeiros romances. Porém, a independência teórica em relação às escolas o forçou a caminhar solitariamente e abandonar progressivamente as sociedades de que participara. A reprovação de amigos pela falta de atenção coincide com o esforço do crítico em aplicar aquele método literário à sua própria obra. Machado passou ao largo dos "dramas de atualidade", aproximando-se, desde o início, do teatro de caracteres, movimento iniciado pelos moralistas franceses.

É preciso dizer que o século XVII celebrou o compêndio de ditos e máximas de La Bruyère, recolhidos em Caracteres ou costumes deste século. Esse livro retrata criticamente os tipos sociais da alta corte francesa, satirizando seu comportamento vaidoso, hipócrita e cheio de superficialidades. Comum nos salões dessa época, ao drama e ao estudo de caracteres acrescentava-se a forma proverbial. Os personagens discorriam sobre um tema, uma charada ou um provérbio popular de tal modo que o espectador pudesse compreendê-lo ou decifrá-lo. Um método semelhante de composição é adotado em Ressurreição, onde o autor nos adverte em prefácio a tentativa de ensaiar sobre um pensamento de Shakespeare e realizar "o contraste de dois caracteres" (ASSIS, 2015f, p. 233).

De acordo com Antonio Candido (1970, p. 21-22), Machado de Assis constrói as suas narrativas ensaiando sobre um dilema filosófico, com o objetivo de gerar perplexidades e paradoxos. Em geral, o dilema será representado a partir da situação inicial e do contraste entre os caracteres. É possível dizer, ainda, que a origem deste método de composição tem rastros no laboratório da crítica teatral.

Apesar de tentar uma dramaturgia incomum para a época, baseada no estudo de uma situação e na contrariedade de caracteres, as primeiras peças de Machado de Assis foram alvo de críticas de escola. Situadas na alta classe fluminense, elas colocavam em cena as intempéries de um triângulo amoroso. Por um lado, dizia-se que as peças funcionavam para mero entretenimento intelectual. Apesar de representarem ironicamente o bom gosto e o estilo de vida burgueses, elas não cumpriam o vaticínio realista de elevação moral da plateia. Por outro lado, as peças eram construídas através de longos diálogos, enfraquecendo a dramaticidade própria da arte. Quintino Bocaiuva, em crítica avassaladora, afirmou que o drama de Machado não primava pela forma 
artística, apesar de primar pela poeticidade e pelo alcance psicológico (ASSIS, 2008, p. 20).

Machado ainda escreveu outras comédias proverbiais, tais como Tu só, tu, puro amor (1880), Não consultes médico (1896) e Lição de botânica (1906), mas as críticas de Bocaiuva foram definitivas para a avaliação negativa do teatro machadiano. À derrota artística se seguiu outra de caráter político e ideológico: a defesa pela subvenção estatal do teatro foi em vão. Nos anos que seguiram, o governo pouco ou nada investiu na formação de atores e na cena artística nacional. Joaquim Nabuco, José de Alencar e outros divulgadores do teatro denunciaram o seu estado indigente. A decepção com o teatro foi ainda maior porque o exagero quanto aos preceitos das escolas, agora ultrarromânticas e ultrarrealistas, deteriorava a arte e o gosto do público, servindo apenas para "desenfastiar o espírito, nos dias de maior aborrecimento" (ASSIS, 2015h, p. 1102). Naquelas circunstâncias, nenhum dos elementos do drama estava adequado: não havia autores bem formados, nem o interesse do público, nem companhias de teatro comprometidas com a descrição de uma essência humana, nem quem as financiasse, tampouco quem se prestasse à crítica fundamentada filosoficamente. A ascensão do teatro musicado foi o golpe de misericórdia para a dramaturgia nacional, que passou a ter maior concorrência estrangeira, distanciando-se do teatro de teses.

O aprendizado por vitórias e derrotas pode ser descrito de outro modo: as diversidades de gênero e de ação são como receituários de um laboratório; testam-se as diferentes combinações até as proporções agradarem. Assim, o itinerário de errâncias é menos o do derrotado do que o do persistente. Aliás, o epíteto Bruxo, celebrado no poema de Drummond, corresponde a essa imagem de um escritor-ensaísta. Com o teatro, o Bruxo pôde ensaiar em laboratório a transformação da tríade dramatúrgica em aspecto formal para a literatura, não mais mimetizada por atores e público, mas por narradores e leitores.

A dialética entre o local e o universal estava prestes a ser ultrapassada. Segundo João Roberto Faria (2008, p. 165), a partir de 1869, Machado de Assis "valorizará cada vez mais em seus textos críticos os dramaturgos que trazem ao palco temas universais. Não por acaso, Shakespeare se tornará cada vez mais presente em seu pensamento". Uma obra artística, pensa Machado, não cumpre seu desígnio moral retratando os valores éticos de uma classe, mas "Uma obra é moral - lembra-me ter lido em Mme. de Staël - se a impressão que se recebe é favorável ao aperfeiçoamento da alma humana... A moralidade de uma obra consiste nos sentimentos que ela inspira" (ASSIS; FARIA, 2008, 
p. 388). Em 1869, ele é ainda mais incisivo do que essa citação à Mme. de Staël. Ao escrever sobre a atriz italiana Adelaide Ristori, Machado decreta, lançando mão de um paradoxo: "Eu não creio nos intuitos moralizadores do teatro, nem penso que Tartufo matasse a hipocrisia" (ASSIS; FARIA, 2008, p. 497-498). É que não bastava desmascarar o personagem de Molière, o típico falso devoto que viola a moral cristã para benefício próprio, para que se elimine a corrupção e a hipocrisia, uma vez que esses vícios de comportamento são, no melhor dos casos, elementos da estrutura social e, no pior, características indispensavelmente humanas. Do mesmo modo, não basta estudar a forma, as leis e as regras do estilo teatral se não se reconhecer "a parte universal dos sentimentos" (ASSIS; FARIA, 2008, p. 499). Esse paradoxo estava tão presente que o dramaturgo brasileiro começou a escrever uma peça denominada $O$ casamento de Tartufo, cujos originais estão perdidos. A representação ficcional, reprodução de práticas sociais pelos personagens, não revelava apenas indivíduos em seus arredores. A intenção realista, fundamentada em uma antropologia negativa, passava a testar se algum personagem justificava a manutenção daquelas regras morais. Quando ninguém sobrevive ao teste, então é o caso de considerar, para além de qualquer realidade local, se não haverá um "instinto secreto", como diz Pascal (2005, p. 53), "que os faz buscar o divertimento e a ocupação exterior, que vem do sentimento de suas misérias contínuas". Desse ponto em diante, a ficção machadiana iniciará o processo de relativização irônica da moral cristã, apresentando uma solução ficcional ao "paradoxo" de Tartufo.

\section{Referências}

ASSIS, Joaquim Maria [M-as]. Revista de teatros. O Espelho, n. 2, p. 8, 11 set. 1859. Disponível em: <http://memoria.bn.br/DocReader/700037/14>. Acesso em: 19 jan. 2019.

ASSIS, Joaquim Maria Machado de; FARIA, João Roberto. Machado de Assis: do teatro. São Paulo: Perspectiva, 2008.

. Correspondência de Machado de Assis. Tomo I, 1860-1869. Coordenação de Sérgio Paulo Rouanet; reunida, organizada e comentada por Irene Moutinho e Sílvia Eleutério. Rio de Janeiro: ABL; Biblioteca Nacional, 2008.

Antônio José. In: Obra completa em quatro volumes. São Paulo: Nova Aguilar, 2015a. v. 3, p. 562.

. Ao acaso. 10 de janeiro de 1865. In: Obra completa em quatro volumes. São Paulo: Nova Aguilar, 2015b. v. 4, p. 221-225. 
Ao acaso. 19 de setembro de 1864. In: Obra completa em quatro volumes.

São Paulo: Nova Aguilar, 2015c. v. 4, p. 174-178.

. Comentários da semana. 11 de dezembro de 1861. In: Obra completa em quatro volumes. São Paulo: Nova Aguilar, 2015d. v. 4, p. 35-38. Ideias sobre o teatro. In; Obra completa em quatro volumes. São Paulo: Nova Aguilar, 2015e. v. 3, p. 1010-1017. Ressurreição. In: . Obra completa em quatro volumes. São Paulo: Nova Aguilar, 2015f. v. 1, p. 230-307. . Revista Dramática. José de Alencar: Mãe. In: Obra completa em quatro volumes. São Paulo: Nova Aguilar, 2015g. v. 3, p. 1019-1023.

. Semana literária. O teatro nacional. In: Obra completa em quatro volumes. São Paulo: Nova Aguilar, 2015h. v. 3, p. 1102-1107.

CANDIDO, Antonio. Esquema de Machado de Assis. In: Vários escritos. São Paulo: Duas Cidades, 1970. p. 15-31.

CEI, Vitor. A voluptuosidade do nada: niilismo e galhofa em Machado de Assis. São Paulo: Annablume, 2016.

COUSIN, Victor. Du vrai, du beau et du bien. 2. ed. Paris: Didier, 1854.

FARIA, João Roberto. Machado de Assis e o teatro. Revista Brasileira, Rio de Janeiro, v. 55, p. 153-184, 2008.

MACEDO, Ubiratan Borges de. A ideia de liberdade no século XIX: o caso brasileiro. Rio de Janeiro: Expressão e Cultura, 1997.

MAGALHÃES, Gonçalves de. Fatos do espírito humano. Petrópolis: Vozes; Academia Brasileira de Letras, 2004.

MAGALHÃES JÚNIOR, Raimundo. Vida e obra de Machado de Assis. 2. ed. Rio de Janeiro: Record, 2008. v. 1.

MAIA NETO, José Raimundo. O ceticismo na obra de Machado de Assis. Rio de Janeiro: Annablume, 2007.

MARTINS, Alex Lara. Machado de Assis: o filósofo brasileiro. Porto Alegre: Fi, 2017.

MASSA, Jean-Michel. A juventude de Machado de Assis. Rio de Janeiro: Civilização Brasileira, 1971.

MONTÉGUT, Émile. Un beau mariage, de Augier et Foussier. Revue des Deux Mondes, $2^{\mathrm{e}}$ période, p. 748-756, mars-avril $1859 \mathrm{a}$, première quinzaine. . Le Théâtre et la nouvelle littérature dramatique (Un Père prodigue, de M. Alexandre Dumas fils). Revue des Deux Mondes, $2^{\mathrm{e}}$ période, tome 24, p. 965$983,1859 b$.

. Rédemption, de M. O. Feuillet. Revue des Deux Mondes, $2^{\mathrm{e}}$ période, tome 30, p. 236-247, nov. 1860, première quinzaine.

PAIM, Antonio. História das ideias filosóficas no Brasil. 5. ed. rev. Londrina: UEL, 1997.

PASCAL, Blaise. Pensamentos. Trad. Mário Laranjeira. 2. ed. São Paulo: Martins Fontes, 2005. 
Machado de Assis em Linha — Universidade de São Paulo

http://machadodeassis.fflch.usp.br

PLANCHE, Gustave. Les drames et les comédies du temps. Revue des Deux Mondes, $2^{\mathrm{e}}$ période, tome 6, p. $699-712$, déc. 1856 , première quinzaine.

SCHWARZ, Roberto. Machado de Assis: um mestre na periferia do Capitalismo. 2. ed. São Paulo: Duas Cidades, 1991.

SOARES, Antônio Joaquim de Macedo. O teatro, a concorrência e o governo. Diário Mercantil, Rio de Janeiro, Typographia do Correio Mercantil, n. 330, p. 1-2, 14 dez. 1861. Disponível em: <http://memoria.bn.br/pdf/217280/per217280_1861_ 003 30.pdf $>$. Acesso em: 30 out. 2018.

VIANNA, Glória. Revendo a biblioteca de Machado de Assis. In: JOBIM, José Luís (Org.). A biblioteca de Machado de Assis. 2. ed. Rio de Janeiro: ABL; Topbooks, 2008. p. 99-274.

ALEX LARA MARTINS é doutor em Filosofia pela Universidade Federal de Minas Gerais. Fez a graduação em Filosofia na UFMG, com formação complementar aberta e ênfase em Letras, e mestrado em Filosofia pela mesma universidade. Possui, ainda, especialização em Gestão Pública. É professor do Instituto Federal do Norte de Minas Gerais desde 2013. Como pesquisador, atua principalmente nos seguintes temas: Filosofia no Ensino Médio, Literatura e Filosofia, Ceticismo, Machado de Assis, Teoria da ficção e Filosofia no Brasil. Este artigo contou com o apoio do Programa PBQS do Instituto Federal do Norte de Minas Gerais. E-mail: alexlm@bol.com.br

Recebido: 16.11 .2018

Aprovado: 20.01.2019 